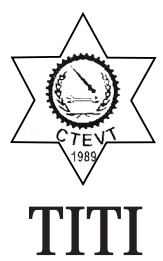

DOI: http://dx.doi.org/10.3126/jtd.v3i0.18230

ISSN: 2392-4578(Online)

\title{
Understanding Trainers Implementing their Occupational Skill in Delivering Training
}

\author{
Pashupati Joshi \\ Regional Monitoring Officer, Skill Development Project (SDP) \\ Council for Technical Education and Vocational Training (CTEVT) \\ Sanothimi, Bhaktapur, Nepal \\ Email for Correspondence: pashupatijoshi@yahoo.com
}

\begin{abstract}
The objective of this study was to understand the vocational instructional implementation of occupational skill while delivering hardware maintenance training in Kavraplanchok district of Nepal. A case study research design was applied while carrying out this study. All together five participants were purposefully selected for the study. The study reveals that the training was taken for granted by the trainees. Lack of equipment, tools and resources, same teaching learning methodology, focus on tradition lecture methods and limited time frame were the hindering factor during the implementation of occupational skills by the trainers.
\end{abstract}

Keywords: Training, transfer, Technical Vocational Education and Training (TEVT)

\section{Introduction}

Training is a means to an end. It is not an end itself. The purpose of any vocational skill training is to prepare individuals for livelihood by being engaged in a specific occupation/s in the formal or informal sector economy (Subedi, 2008). Skill development project (SDP) of council for technical education and vocational training (CTEVT) is providing vocational training with financial support from Asian Development Bank (ADB) throughout Nepal. But the question is that whether the trainers are successful in transferring their occupation skills while delivering the training of not. To understand and explore the answer this study was carried out purposively with five participants who were directly involved in the vocational training held in Kavraplanchok district of Nepal.

\section{Literature Review:}

Transfer of training plays an important aspect to enhance skill of an individual (Subedi, 2008) which further leads economic development of an individual. Subedi (2008) conducted a research on transfer of training with the purpose of examining the extend of transfer and to identify factors influencing in the context of civil and corporate sector organizations of Nepal. The research shows that actual rate of transfer of training proportionately depends upon the extend of pre training, knowledge, training job relevance and the rate of incomprehensive in any 
course or programme. The extend of transfer of training provided to the employees of the organization, nongovernmental sector is higher than that of civil sector (government) organization in Nepal.

Nepal's Technical and Vocational Education and Training (TVET) policy has also highlighted three key objectives 1) Ensure access and equity to those who are interested to participate in TVET programmes through massive expansion of the programmes 2) provide market based quality TVET programs and recognize prior learning and 3) coordinate TVET providers and stakeholders and stakeholders for effective and efficient use of resources. In this regard to achieve the objectives the key policy are 1) massive expansion of TVET programs 2) inclusion and access in TVET programs 3) firm integration of TVET programs and pathways 4) quality and relivency of TVET programs and 5) sustainable financing in TVET (Lamichhane, 2013).So from the above literature it can be said that there is policy for effective training and also prevalence of effective transfer of training in TVET sector.

\section{Case Study as My Research Method}

Case study research method is "an empirical inquiry that investigates a contemporary phenomenon within its real-life context; when the boundaries between phenomenon and context are not clearly evident; and in which multiple sources of evidence are used" (Yin, 2003). This method enables a researcher to closely examine the data within a specific context. In most cases, a case study method selects a small geographical area or a very limited number of individuals as the subject of study. Case studies, in their true essence, explore and investigate contemporary real-life phenomenon through detailed contextual analysis of a limited number of events or conditions, and their relationships (Zainal, 2007). Case studies are considered useful in research as they enable researchers to examine data at the micro level. Case studies can be a practical solution when a big sample population is difficult to obtain (Zainal,
2007). So the researcher investigated the contemporary real life phenomenon of TVET instructors and trainees through detailed contextual analysis of a limited number of participants, and their relationships.

The qualitative case study facilitates to explore the phenomena within the context using variety of resources. It helps to see the issues through variety of lenses which allow for multiple facets of the phenomena to be revealed and understood (Baxter \& Jack, 2008). So, the researcher explored the phenomena within the context using the variety of resources. Study on the understanding of trainers implementing their occupational skills in Nepal fits here as it focuses to answer the process question (Yin, 2003). So the researcher has chosen the social constructivist worldview and comprises interview and observation. Social constructivism develops the subjective meaning of participants' experiences towards certain objects or things which are varied and multiple (Creswell, 2008). In this research, there were five participants. The five participants' occupational background was computer hardware maintenance and they were from Kavraplanchok district of Nepal.

\section{Understanding my participant perception towards training}

Ritesh (Pseudo name, 27 years, male, computer hardware trainer, Kavraplanchok) says that: It is very difficult for me to train my participants. They are not of same level and they also take training just for granted. When they take training just for granted, it makes it difficult to transfer the knowledge and experience that I have.

From the above narrative inquiry of my participant, I came to understand that it is difficult to train participants who are not serious towards the training and the understanding level of the participants is also varied.

Hari (Pseudo name, 24 years, male, computer 
hardware trainer, Kavraplanchok) says that In my training I have 20 students but the availability of computer is not enough. I can't teach all my trainees properly with the limited number of computers.

From the above narrative inquiry of my participant, it clearly means that lack of sufficient tools and equipment also hampers the effective transfer of skill and knowledge during a training. During my field work I found out that only two computers were available for 20 students for the hardware maintenance training.

Shyam (Pseudo name, 17 years, male, computer hardware trainee, Kavraplanchok) says that: I am very happy with the training. I am learningnew skills in computer hardware and maintenance. But sometimes I feel lazy and bored because my trainers always use same method to teach or the way the trainers teach us demotivates me to learn.

From the narrative inquiry of my participants, I come to understand that the trainers should use different methodology during the teaching learning process to teach their trainees. Use of same methodology in teaching and learning process can be boredom and can de motivate learners to learn the desired skills.

Monaj (Pseudo name, 21 years, male, computer hardware trainee, Kavraplanchok) says that: trainers are very good in delivering theory class. They have very good presentation skills but in case of practical class I am not so satisfied. They just do demonstration and leave $i t$. We also have limited tools and instrument so how can we learn. We sometime can only observe the practical session without getting any opportunity to practice the demonstrated skill.

So again from here it is clear that the trainers should be actively involved in both theory and in practical class.
Krishna (Pseudo name, 32 years, male, Training coordinator, Kavraplanchok) says that: It is very difficult to complete the training in 390 days. We have lots of skills to train in limited time schedule and also there is a challenge for us to maintain all the resources and environment in this rural area.

From the above interview with my participant, it can be said that lack of time can make it difficult to provide all the desirable skills to the trainee. Likewise it is also a challenge to create a good training environment in the rural areas of Nepal due to the turnover of trainers, who are always seeking for a better opportunity.

\section{Findings and Discussion \\ Findings}

My objective was to understand the perception towards training in TVET sector in which I found multiple perception through narrative inquiry. I found that trainees feel difficult to implement their knowledge, experience and skill. Similarly lack of tools and equipment also hinders the trainees while learning a new skills. Likewise I also found out that that by using the same method in teaching and learning process also hinders the teaching learning process. I also found out that 390 days training was not sufficient for trainees to learn all the desirable skills in computer hardware maintenance.

\section{Discussion of the Findings}

From the narrative inquiry of my participants I have come to the conclusion that if the participant take the training just for granted or are not serious towards the training, than it is very difficult to transfer the knowledge and skills. Haccoun and Saks (2009) also states that it's very difficult to conduct a training if trainees take the training for granted. Lack of tools and equipment also hamper in transfer of training. Grossman (2011) also reveals that lack of resources and training support material hampers effective transfer of training in TVET sector. Likewise trainer should also adopt different training methodology 
and skill while teaching to make effective transfer of training. Cornford (2002) also states that in vocational training, participant based learning approach is most important and frequent change in teaching learning approach makes effective transfer of training in vocational training.

Trainees should be actively involved in both practical and theory class to make effective transfer of training. If trainers were only successful in giving good quality lecture but failed to demonstrate their skill in practical session than it hinders transfer of skills/knowledge. Bunning (2016) also states that vocational TVET teacher should focus on transferring skills to their trainees rather than providing theoretical because TVET refers to the transformation of skills for the transformation of society. Lack of sufficient timeframe also hinders trainees to learn the desirable skills. Similarly teaching in rural areas also hinders effective transfer of training. Koirala and Dhungana (2015) also states that teaching in rural area in Nepal demotivates to teach and technical teachers were always seeking new opportunities in urban areas.

\section{Conclusion}

To understand the training transfer rate of occupational skills after delivering the training, I found out that the major hindering factors were lack of seriousness from the trainee's side who seem to take the training just for granted. Lack of tools, equipment and resources during the training and boredom during the teaching learning process due to the use of same teaching learning methodology that focused on traditional lecture method. Finally not providing enough time to transfer the skills and knowledge during thetraining also hampers the teaching learning process. So transfer of training is an important aspect in TVET but it is difficult to apply in rural training environment.

\section{References}

Baxter, P., \& Jack, S. (2008). Qualitative case study methodology: Study design and implementation for novice researchers. Ontario,Canada: McMaster University.
Cornford, I. R. (2002). Two model for promoting transfer: a comprehensive and critical analysis. Journal of vocational education and training vol 54 (1). doi: 10.1080/13636820200200189

Creswell, J. W. (2008). Qualitative inquiry and research design. New Delhi: Sage.

Grossman, R. (2011). The transfer of training: what really matters. International journal of training and development vol 15(2). Retrieved from http://pdfs.semanticsscholar.org/ab9d/ 00729ef9e. .8d.pdf

Haccoun, R. R., \& Saks, A.M. (2009). Training in the 21st century: some lesson from the last one. Canadian psychology, 39(1). Retrieved from www.project.ict.usc.edu/itw/gel/haccoun trainingin 21 stcentcanadianJP98.pdf

Koirala, A., \& Dhungana, G. (2015). Understanding technical instructional motivational practices in vocational training center, Morang, Nepal. Journal of Training and Development 1(1), 33-37.

Lamichhane, R. H. (2013). Strategic direction for CTEVT for skilling Nepal. Technical and vocational education and training development journal 1 (13), 14-22.

Yin, R. K. (2003). Case study research design (3rded.). New Delhi, Sage.

Zainal, Z. (2007). Case study as research method. Malaysia: University Technology. 